\author{
ADVANCED INTERNATIONAL JOURNAL OF \\ BUSINESS, ENTREPRENEURSHIP AND SMES \\ (AIJBES) \\ WWW.aijbes.com
}

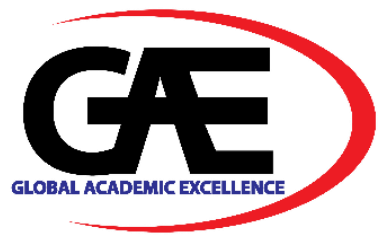

\title{
THE ASSESSMENT OF INSTAGRAM EFFECTIVENESS AS MARKETING TOOLS ON INDONESIA FASHION LOCAL BRAND
}

\author{
Ivani Nafisa Putri ${ }^{1 *}$ \\ 1 School of Business and Management, Institut Teknologi Bandung, Indonesia \\ Email: ivani_nafisa@sbm-itb.ac.id \\ * $\quad$ Corresponding Author
}

\section{Article Info: \\ Article history: \\ Received date: 24.08 .2021 \\ Revised date: 25.09 .2021 \\ Accepted date: 20.10 .2021 \\ Published date: 01.12.2021 \\ To cite this document:}

Putri, I. N. (2021). The Assessment Of Instagram Effectiveness As Marketing Tools On Indonesia Fashion Local Brand. Advanced International Journal of Business, Entrepreneurship and SMEs, 3 (10), 01-13.

DOI: $10.35631 /$ AIJBES.310001.

This work is licensed under CC BY 4.0 (ㅇ)(1)

\begin{abstract}
:
Fashion local brands are brands of fashion clothing local to a particular country, manufactured and produced locally, including the ones in Indonesia. Fashion is always developing and creating the latest trend in which is a big potential for local fashion brands to take this opportunity because consumers are becoming more selective when it comes to selecting superior, long-lasting, and practical products. In Indonesia, the Fashion Industry is one of the subs that contribute to the creative industry, accounted for $28.29 \%$ of the whole creative industry, and ranked 9th in the Global Revenue Ranking. In addition, the current pandemic condition has pushed many brands to close retail stores and switched to almost entirely digital operations. Among many social media platforms used by brands, Instagram has been identified as the most efficient tool for reaching out to customers and marketing a business. However, the way local fashion brands use Instagram as a marketing tool has not always been effective. This research aims to assess the effectiveness factors of Instagram in local fashion brands that have a high engagement in purpose to make them as the benchmarks about the content strategy in building high online engagement that makes Instagram as a marketing tool effective. The data was collected through Instagram analytics software, HypeAuditor, and Analisa.io towards a total of 50 Instagram account fashion local brands with a high number of engagements according to HypeAuditor Instagram Engagement Rate Calculator. The data analysis is processed using Microsoft Excel and Smart PLS. The result shows that all independent variables have a positive relationship to online engagement and the effective factors for local fashion brand Instagram accounts are Entertainment, Tag, Weekdays, and Peak hours factors. The brand could utilize posting feeds containing entertainment and information content while also posting it during peak hours and weekdays.
\end{abstract}


Keywords:

Fashion Local Brand, Social Media Marketing, Instagram, Online Engagement, PLS-SEM, Quantitative Method, Qualitative Method

\section{Introduction}

Fashion is something that differs greatly. In which different not only in eras, but also in the same century, between different ages, social backgrounds, occupations, and even places. Based on the etymology, the words "fashion" and "clothing" appear to be used synonymously. However, although fashion conveys a variety of different social interpretations, clothing refers to the generic raw materials that a person wear. The word "fashionista" was created as a means of identifying someone who is committed and interested in fashion, and the development of this word is reflective of the role fashion and trends play in the modern era (Kawamura, 2018) In Indonesia, the Fashion Industry is one of the subs that contribute to the creative industry. The creative industry has a significant role to play in Indonesia's economic development. The Central Bureau of Statistics reported that the growth rate of the creative industry was 7.6 percent by (year) or for around Rp641.82 trillion. This indicates that the artistic industry in Indonesia plays a crucial role in the growth rate of national GDP. Moreover, the fashion industry accounted for $28.29 \%$ of the whole creative industry in Indonesia (Hendrayati \& Gaffar, 2016). According to statistica.com in 2019 Indonesia ranks 9th with Global Revenue Ranking with the Revenue in the Fashion segment projected to reach US\$9,813 M in 2020.

Since we are currently getting the adverse effect from a worldwide pandemic, known as COVID-19. The virus has been affecting international industries and activities by forcing those who can operate from home and those who cannot sacrifice their health and welfare to perform critical services. In order to fight against the COVID-19, many local fashion brands also closed their retail stores and switched to almost entirely digital operations (Haywood, 2020). When the world depends more than ever on technology as a platform to build consistency for learning, shopping, socializing and working. (Haywood, 2020).

In this era of digital, the existence of technology and the internet for humans is increasingly unavoidable. It cannot be denied that the internet has brought rapid changes to several aspects of human's life, Including fashion local brand business. Fashion local brands need a lot of strategy to market their products that are delivered by social media, because in business social media is one of the channels that supports communication in marketing quickly and profitably compared to selling directly to the market (Zilfania, 2014). According to Al-Ghamdi and Reilly (2013), 83\% marketers put high emphasis on social media due to their significant role in reaching and maintaining clients and, most notably, in generating new market opportunities. Social media has made it very easy for entrepreneurs to reach potential customers and tell them about their products. They also provide them with a strong forum to market and support and offer their innovations and goods as well. Thus, local brands should have a key approach. The first step is to choose the right social media, they need to focus in order to begin to market their products (Kusumah, 2015). 


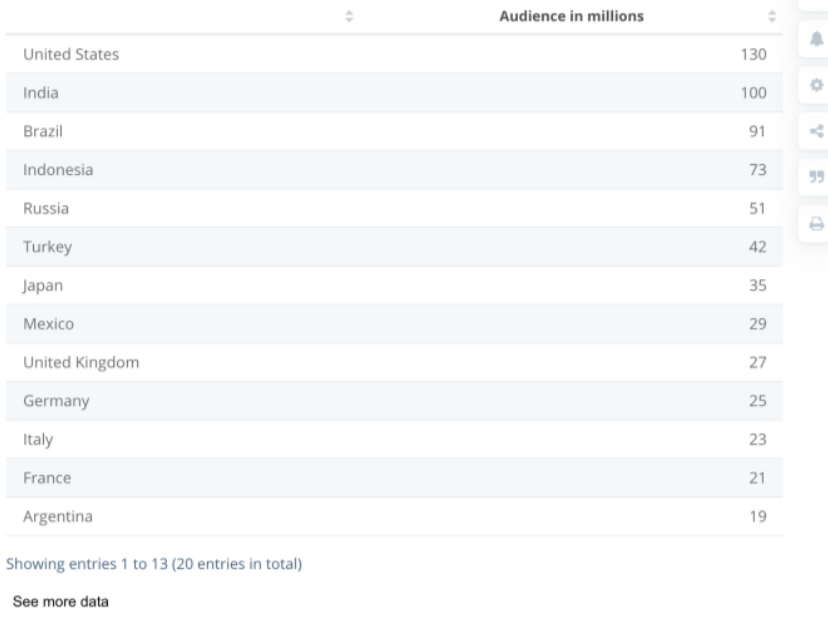

Figure 1: Leading Countries Based on The Number of Instagram Followers User As Of Source: Statista, 2019

July 2020

According to Instagram's statistics below, the number of its users has reached 854,5 million as of July 2020 with Indonesia ranked 4th and reached 73 million users and Instagram users will potentially continue to grow and more of the customers can be obtained through Instagram. It is certainly a must that local fashion brands should also be able to take this as an opportunity to expand their business (Kusumah, 2015).

According to Muder (2015), online engagement in social media is the main factor for measuring the effectiveness in social media. However, although the Instagram application has been chosen as the most effective social media with the highest engagement for consumers among other social media such as Facebook, Twitter, WhatsApp, Tik Tok, the way local fashion brands use Instagram as a marketing tool has not always been effective. As evidence, from a total of 150 local fashion brands' Instagram accounts that the researcher already measured through HypeAuditor rate engagement calculator, it has been found that more than $50 \%$ of them are proven to have poor to average online engagement level. One of the examples, the researcher has chosen two local fashion brand accounts with high and poor online engagement level as followed:

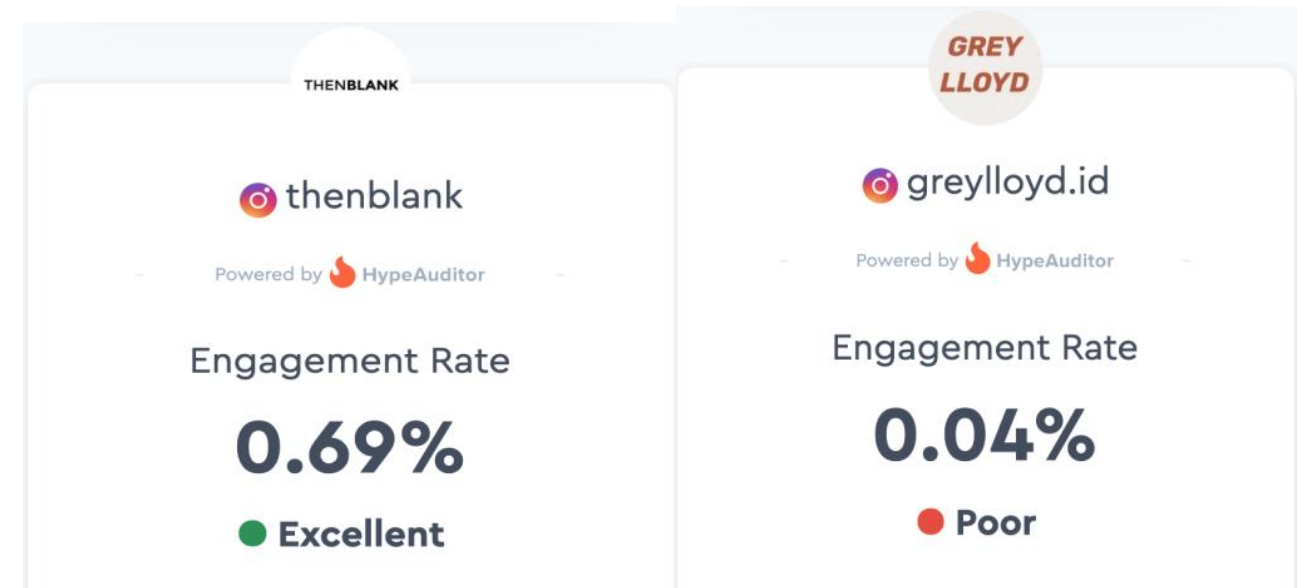

Source: hypeauditor.com

Figure 2: Local Fashion Brand's Instagram Engagement Rate

Copyright $\odot$ GLOBAL ACADEMIC EXCELLENCE (M) SDN BHD - All rights reserved 
The figure shows that there are local fashion brands that have a high engagement and there are some others that do not, like @ thenblank has $0.69 \%$ of engagement rate that is measured as excellent online engagement meanwhile @ greylloyd.id only has $0.04 \%$ of engagement rate that measured as poor online engagement. A study found by Rodriguez et al. (2012) argues that an effective social media practice will lead to sales processes, creating opportunities, and relationship management with customers. Thus, if businesses cannot optimally utilize social media in an effective way, it will be very susceptible for them to obtain those advantages. Hence, this research aims to assess the effectiveness factors of Instagram in local fashion brands that have a high engagement in purpose to make them as the benchmarks about the content strategy in building high online engagement that makes Instagram as a marketing tool effective.

This research will help the fashion local brand that have a problem with Instagram effectiveness by conducting a research through determining the factors that make Instagram become effective and giving solution with recommend the content strategies that are suitable for fashion local brands' Instagram that have a poor online engagement to increase their online engagement in purpose to make their Instagram effective as a marketing tool.

\section{Literature Review}

This chapter focuses on compiling the theories, frameworks, and principles that support this research. It also includes the conceptual framework and previous research findings. The literature research in this study was focused on fashion local brands, social media marketing practice, content type, social content, posting time and online engagement.

\section{Fashion Local Brand}

Fashion Local Brand means to brands of fashion clothing local to a particular country, manufactured and produced locally. While numerous studies on different aspects of fashion clothing brands have been carried out, very few studies have concentrated on local fashion clothing brands (Rahman \& Mannan, 2018). Indonesia owns a variety of local brand products, including those in the fashion industry (Wixsite, 2015). Local fashion brands have grown in popularity in recent years, and Indonesian customers are proud to use Indonesian local brands (Meryana, 2011)

\section{Social Media Marketing}

These days, the entire purchasing process which begins with assumptions and knowledge searches and continues with the sharing of real experience, is most frequently carried out online on social media networks. Since consumers are now spending more and more time on the internet, customers use social networks to search for information about new goods and services and also investigate reviews from other customers online before making a buying decision. This is why social media is often referred to as a multimedia word of mouth (Kabani, 2010). Social media marketing is certainly the main way for targeting consumers in this generation. The Internet has provided a lot of opportunities for businesses to connect with their customers, but at the same time it has made the entire thing more complicated. If the marketers do not know the correct kind of approach and experience of social media marketing it will end up ineffectively. There are a lot of types of social networking sites including facebook, linkedin, twitter and Instagram (Hellberg, 2015). 


\section{Instagram}

Instagram is a free app that allows everyone to post videos and pictures (Wood, C. 2015). Nowadays Instagram has also grown to include clips, posts, videos and live programs, but the main thing is always the images. Based on Instagram's own study, Instagram is a place where users show themselves creatively and are linked to things that matter to them (Business Instagram, 2017). Instagram certainly is an effective platform to reach the consumers. Instagram has at the moment around 1 billion monthly active users and more than 25 million business accounts. Currently, almost 5 million photos are shared on Instagram every day (Sharma R, 2018).

\section{Content Type}

Content type is a marketing strategy that focuses on developing and delivering useful, appropriate, and reliable content in order to attract and maintain a specific audience and to drive profitable consumer action. The Uses and Gratifications (U\&G) theory is a common method used by technology and media researchers to understand individuals' goals and motives for engaging with various types of content. Previous applications of U\&G theory to brand communities and social media revealed that consuming entertaining and informative content is a significant factor for engagement in brand communities (Dholakia et al., 2004; Raacke and Bonds-Raacke 2008), with entertainment having a stronger influence (Park et al., 2009). Furthermore, Muntinga et al. (2011) identify Remuneration by sweepstakes as the third and least frequently cited justification for engagement. Based on the literature, a research model developed by Cvijikj and Michadelles (2013) divided content type into three categories: Entertainment, Information, and Remuneration.

\section{Entertainment}

Entertainment refers to how exciting the content of brands on social media is. Entertainment content in Instagram includes humorous videos, teasers, slogans and wordplay. Relaxation, emotional release, pleasure, and satisfaction with an issue or routine are all associated with entertainment (Muntinga, 2011). The entertainment type Instagram post may be linked to unique characteristics of the photo where users can enjoy and admire the photos posted by others (Casalo, 2017). In Instagram posts, entertainment content would be games, tips and tricks, national day commemoration, quotes and any of interactive video.

\section{Information}

Information is the content about how the brand shows specific products, brands and related marketing activity. According to Park et al. (2009) research, Facebook users plan to research key points about relevant goods and services in order to meet their knowledge and information needs. In Instagram posts, information content would be all of the information posts about the brand and product.

\section{Remuneration}

Remuneration is the kind of post content that provides giveaway, promotions, coupons, special offers and other offers to attract customer's attention, remuneration is another primary motivator that drives people to connect with brands on social media is the expectation of receiving something in return, such as money or a reward (Wang and Fesenmaier, 2003).

\section{Social Content}

Social content is the content of post's caption that coded to record the presence of social content in the form of hashtags and tags which are marked by the use of the '\#' symbol before clickable 
words, phrases, or acronyms used to denote common topical posts and tagging of other users, which is indicated by the use of the '@' symbol before a clickable user name (Adegbola, et al., 2018).

\section{Tag}

Tags play an important role in social media as well since each tag can direct a user to unique content shared within a community. Tags, according to Golder and Huberman (2006), connect social media users, media, and content in an ever-expanding circle, resulting in increased exposure. Tags with the '@' symbol on Instagram serve as a 'call to action,' making it easier for other social media users to get involved with a topic or content (Leimkuehler, 2016), and this is especially important for photos.

\section{Posting Time}

According to Kumar et al. (2006) Scheduling including posting time was already known as an important component of marketing strategies that could eventually result in increased sales. In most cases, online advertisement assumes getting a time and space slot(s) on an online site where marketing material will be shown. The timing in social media posting is important because it influences the engagement toward the post (Cvijikj and Michadelles, 2013). Previous research on temporal engagement patterns revealed that the majority of Facebook user activities occur during the workday (Golder et al. 2007).

\section{Weekday}

A weekday is a day that does not fall on a weekend. Monday, Tuesday, Wednesday, Thursday, and Friday are considered weekdays in most countries, but Saturday and Sunday are not. Posting in social media on weekdays refer to post between Monday and Friday (Cvijikj and Michahelles, 2013)

\section{Peak Hour}

Peak hour is a time of day when a large number of people have gathered. According to Cvijikj and Michahelles (2013) peak hours in social media are recorded from 4PM to 4AM. Moreover, a study by Cvijikj et al. (2013), dinner and in-between times are categorized as peak hours.

\section{Online Engagement}

According to Leary (2018) people often turn to the Internet for inspiration, entertainment, information and guidance. Advice focused on what to purchase, where to buy and how to buy from social media is a perfect way to promote a brand, but it also has the difficulty of being a platform where marketers need to be continuously involved. Consumers want knowledge, service, support with their problems and a sense of interaction. Consumer interaction is about motivating customers to be engaged with the brand. If this is done right, it will allow the business and the brand to expand and build more loyal customers. By allowing consumers to connect to the brand and by creating a relationship, the brand would be able to receive valuable knowledge from their consumers. Finding needs and trying to make it easier to see if there will be any updates or enhancements that could or should be made.

\section{Conceptual Framework}

Following the evaluation of the previous related research, a structure and variables are developed from the literature review conducted in this chapter. The following is the suggested conceptual structure for this study: 


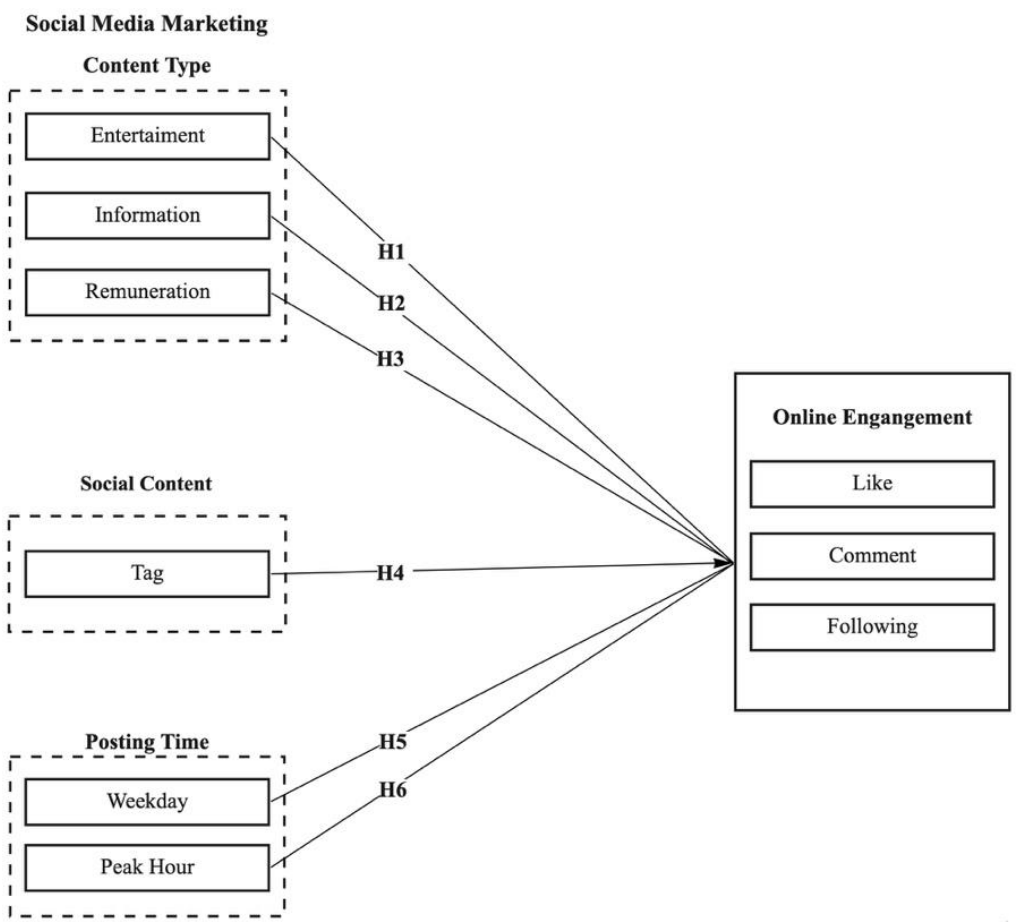

Source: Author's Interpretation

Figure 3: Conceptual Framework

H1. Entertainment is positively related to online engagement.

$\mathbf{H}_{2}$. Information is positively related to online engagement.

H3. Remuneration is positively related to online engagement.

H4. Tag is positively related to online engagement.

H5. Weekday posing time is positively related to online engagement.

H6. Peak Hour posting is positively related to online engagement

\section{Methodology}

This section depicts an overview of the research process, which includes exploratory research to do an exploration regarding the effectiveness factors of Instagram in local fashion brands that have a high engagement in purpose to make them as the benchmarks about the content strategy in building high online engagement that makes Instagram as a marketing tool effective. Then, continued by the literature review on the results of past research and hypotheses that may aid in conducting this particular research. This research uses both qualitative and quantitative approach in analyzing the data.

\section{Qualitative}

\section{Data Collection}

This study uses Instagram content analysis to gain more deeper insight, Instagram content was observed from the beginning of the research in purpose to find the 50 Instagram accounts that have a high online engagement, what content can be measured and what aspect that is necessary to observe more. In the qualitative approach specifically through Instagram Content Analysis, more specific contents will be identified further in which it is not only determining the engagement level that every account has in number, but also focusing on how contents in every aspect (Entertainment, Information, Remuneration, Hashtag, Tag, Weekdays and Peak Hours) Copyright (C) GLOBAL ACADEMIC EXCELLENCE (M) SDN BHD - All rights reserved 
Volume 3 Issue 10 (December 2021) PP. 01-13 DOI 10.35631/AIJBES.310001

are developed and how its posts are able to lead the account to a higher engagement level. The data gathered from Analisa.io software's feature that show Top Posts with the highest engagement.

\section{Data Analysis}

This study will assess and analyse the Instagram Account performance of 50 Indonesia Fashion Local Brands based on their Content Type, Social type and Posting Time. Further exploration was then undertaken by comparing the assessment outcome with each Indonesia Fashion Local Brand Instagram account in order to obtain new insights into the content marketing of Indonesia Fashion Local Brand. This study would also propose the suggested method of content marketing practice that will have a positive effect on the distribution of value and improve the success of Indonesia Local Brand's Instagram to create a high customer engagement. And then ends with data will be manually coding in which, from the data that the researcher obtained, the researcher will analyse the data using Descriptive Analysis which uses numbers to analyse the data. For example: Frequency and Range. Thus, researcher will get accurate and statistical data.

\section{Quantitative}

To identify the brand's current condition, For the Name of the brand, Username and Content Type (Entertainment, Information and Remuneration) are gathered from a 50 local fashion brand's Instagram account itself by counting the total posts of each aspect in content type. Furthermore, for the Social Content (Tag) and Posting Time (Peak Hours and Weekday) the data that will be gathered through Analisa.io where it shows the exact number of Brands and Instagrammers often the fashion local brand Tagged or Mentioned, posting activity and the weekday total post breakdown. The data from 50 Accounts are sufficient because its already represent the conditions of the research goal which is want to assess the data from the Instagram accounts that have a high engagement so the data is validate from the accounts that have a high Instagram engagement. And the data is reliable because beside the researcher count the data directly one by one, the data exactly shown from the software used during this research. The assessment will be performed through a social media marketing analytics platform, HypeAuditor and Analisa.io. After that, the author uses Partial Least Square (PLS) on the grounds that the variables used in this study are variables that are not directly measurable, which can be measured based on the indicators (manifest variables), and jointly involve the level of measurement error (error). So that the authors can analyze in more detail the indicators of the variables that are not directly measured that reflect the strongest and the weakest latent variables that include the level of error.

\section{Discussion}

\section{Instagram of Fashion Local Brand Analysis}

The study found that most of the 50 accounts with the highest engagement level, in terms of how the Posts feature is used and how it is proven as having positive relationship to the engagement, they have been maximizing the contents posted in a form of entertainment, information, weekday, and peak hours 
Table 1: Instagram Posts Content Aspects

\begin{tabular}{|c|c|c|}
\hline No & Variable & Content \\
\hline 1 & Entertainment & $\begin{array}{l}\text { Games, Funny meme, Tips and trick outfit, Quotes, Animation } \\
\text { picture, Playlist recommendation, Interactive product video, } \\
\text { Interactive traveling video, Video unboxing, Series video, Tiktok } \\
\text { video Mix and Match outfit, Tiktok ootd video, Tiktok dance video, } \\
\text { Funny video, Video animation, IG live video, Video ootd idea }\end{array}$ \\
\hline 2 & Information & $\begin{array}{l}\text { Brand collaboration information with influencer, New collection } \\
\text { information, Product detail information, Review product } \\
\text { information, Back in stock information, Product name information, } \\
\text { Open order information, Bestseller product information, How to } \\
\text { order information, Testimonial information, Website open } \\
\text { information, Brand character information, Restock information, } \\
\text { New platform information, Brand collaboration information with } \\
\text { other brand, Production process information }\end{array}$ \\
\hline 3 & Remuneration & $\begin{array}{l}\text { Giveaway collaboration with other brand, Giveaway new followers, } \\
\text { Discount Sale Day, Giveaway games, Discount cut price, Giveaway } \\
\text { buzzer, Giveaway monthly, Promotion bundle, Giveaway big event, } \\
\text { Sale big event, Free shipping, Discount big event, Discount at store, } \\
\text { Free product, Discount ecommerce, Giveaway Challenge, Giveaway } \\
\text { collaboration with ecommerce, Giveaway collaboration with } \\
\text { influencer, Promotion ecommerce, Giveaway sale day }\end{array}$ \\
\hline 4 & Hashtag & customer nickname or community, product type, popular hashtag \\
\hline 5 & & s another account and partnership influencer \\
\hline 6 & Weekda & Sunday Monday Tuesday Wednesday Thursday Friday Saturday \\
\hline 7 & Peak Hours & $\begin{array}{l}6 \mathrm{AM}, 8 \text { AM, } 9 \text { AM, } 10 \text { AM, } 11 \text { AM, } 12 \text { AM, } 1 \text { PM, } 2 \text { PM, } 3 \text { PM, } 4 \\
\text { PM, } 5 \text { PM, } 6 \text { PM, } 7 \text { PM, } 8 \text { PM, 10 PM }\end{array}$ \\
\hline
\end{tabular}

Source: Author's Interpretation

Furthermore, regarding the content that the brands' Instagram accounts post consist of many types of content characteristics in every aspect as shown on Table 4.8. However, most of the brands' top posts are dominated with (1) interactive product video, (2) Tiktok video mix and match outfit, and (3) quotes for Entertainment, followed with (1) product detail information, (2) product name information, and (3) how to order information for Information, and continued with the top three Weekdays which are (1) Monday, (2) Tuesday, and (3) Wednesday, and lastly is on the Peak Hours of (1) 7 PM, (2) 5 PM, and (3) 4 PM. In addition, according to the Manual Coding direct observation, some Hashtags are also identified as one of the aspects that can be used by brands as a strategy to increase their engagement level through Posts feature. Thus, some related recommendations will be provided.

As a conclusion, this study finds that the 50 Fashion Local Brands have done a good performance on their Instagram accounts. Most of them succeed in doing so because they are able to utilize the Posts feature through maximizing its Social Media Marketing' components on Instagram which are mainly the entertainment, information, weekdays, and peak hours have an effect of $66.35 \%$ on Online Engagement.

\section{Entertainment Relationship with Online Engagement}

In alignment with the previous study which stated that entertainment has a stronger influence toward engagement in brand communities (Park et al., 2009), this study has found that 
Volume 3 Issue 10 (December 2021) PP. 01-13 DOI 10.35631/AIJBES.310001

entertainment has a positive relationship to online engagement. Based on the calculation as shown in the subchapter 4.2.3.4., it is proven that positive relationship hypothesis $\mathbf{H}_{1}$ (entertainment to online engagement) is accepted. It defines that being able to provide audiences with contents that contain Entertainment aspects on Posts feature is one of the main drivers of the audience to engage with Fashion Local Brands' Instagram accounts. Therefore, in order to leverage the level of online engagement, brands should be able to continuously develop contents that contain Entertainment aspects on their Posts.

Entertainment itself refers to how exciting the content of brands on social media is. It includes relaxation, emotional release, pleasure, and satisfaction with an issue or routine (Muntinga, 2011). In accordance with Casalo (2017), this enables audiences to engage with brands by enjoying and admiring the photos posted.

\section{Information Relationship with Online Engagement}

Based on the result of the calculation, it is proven that there is a negative relationship between hypothesis $\mathbf{H}_{2}$ (information to online engagement) in which it is rejected. This is in contrast with the study found by Muntinga et al. (2011) which explains that entertainment and information were discovered to be two of the most important motivators for online interaction with brand-related content in the form of consumption, production, and contribution. However, even so, information posts are considered to be useful as an input to help customers in making their decision upon purchase of the brands' product. Thus, it is not directly having a relationship with online engagement.

\section{Remuneration with Online Engagement}

Although the previous study made by Luarn et al (2015) stated that informational, entertainment, remuneration, and social posts were discovered to be key aspects in driving online engagement, this study finds that according to the calculation performed in subchapter 4.2.3.4., the hypotheses $\mathbf{H}_{3}$ (remuneration to online engagement) is rejected and is proven to have a negative relationship. This, circumstantially in accordance with the study from Muntingal et al. (2011) that explains remuneration is identified by sweepstakes as the third and least frequently cited justification for engagement. Furthermore, even if remuneration is one of the primary motivators that drives people to connect with brands on social media (Wang and Fesenmaier, 2003), the truth is many brands do not use remuneration frequently since once they have to provide such content that contains remuneration, there are some exceed costs that the brands need to pay. For instance, it is indirectly inflicting the revenue that the brands obtained to decrease or an extra expense that needs to be met.

\section{Tags with Online Engagement}

Referring to the study of Adegbola (2018), it found that there is a positive correlation between social content (Tag) with engagement. This is in accordance with the calculation performed in subchapter 4.2.3.4., the hypothesis $\mathbf{H}_{4}$ (tags to online engagement) is accepted. Looking at the result collected from direct observation through Manual Coding, it can be justified that the data gathered are from the total tags of other accounts made by the brands' accounts, which makes it important when it comes to measuring the engagement level of the audience. This implies that in order to enhance online engagement, brands need to utilize the use of tags optimally. According to Leimkuehler (2016), Tags can be described as any text with the '@)' symbol on Instagram serving as a 'call to action,' making it easier for audiences to get involved with a topic or content. Moreover, this is especially important for photos. 


\section{Weekdays with Online Engagement}

According to the calculation performed in subchapter 4.2.3.4., the hypothesis $\mathbf{H}_{5}$ (remuneration to online engagement) is accepted and is proven to have a significant relationship. This is aligned with the previous related study of Cvijikj \& Michahelles (2013). In this study, it is indicated that there is a positive correlation between Posting time on weekdays and online engagement. It implies that in this study, the direct relationship between weekdays (posting time) and online engagement might be highly formed by brands' choice of days upon the posts that have the highest interaction and how it is being maximized continuously. It is being identified from the likes and comments ratios that posting on a weekday was found to be a significant factor for engagement.

\section{Peak Hours with Online Engagement}

In its study, Golder et al. (2007) found out that there is a positive correlation between Posting in Evening and Night (Peak Hours) time with online engagement. These findings are aligned with the calculated result which proves that there is a positive relationship between hypothesis H6 (peak hours to online engagement) in which it is accepted. Since timing in social media posting is important because it influences the engagement toward the post, based on the result, it can be concluded that being able to get brands' content posted at the Peak hours can be one of the main drivers to increase online engagement

\section{Conclusion}

This chapter will summarize the findings from both Instagram data analysis and Instagram content analysis for the entire study.

The effectiveness of Instagram as a marketing tool for brands can be measured from its engagement as explained earlier on subchapter 2.7 that an engagement in social media is the main factor for measuring the social media effectiveness (Muder, 2015). Thus, the researcher clarifies the study by doing an assessment towards 50 accounts of Indonesia Fashion Local Brands with high online engagement. The result shows that the independent variable content type which contains entertainment, variable social content which contains tag and the variable posting time which contains weekdays and peak hours are indicated as having a high online engagement. Thus, all the independent variables then can be implied as having a positive relationship to online engagement. Hence, it can be concluded that according to the research found, Indonesia Fashion Local Brands that able to share their Posts containing factors content type which includes entertainment, social content which contains tag and posting time on weekdays and peak hour can be justified to have utilize their Instagram accounts effectively as marketing tool since it has a high online engagement. In conclusion, the effective factors for local fashion brand Instagram account are Entertainment, Tag, Weekdays, and Peak hours factors and all factors have an effect of $66.35 \%$ on Online Engagement.

This study recommends several strategies for Indonesia Fashion Local Brands managing its Instagram account to attain the highest possible online engagement for the purpose of effectiveness. Based on the audience's behavioral context, the Indonesia Fashion Local Brands could begin by posting feeds through Posts feature containing entertainment and information content. Entertainment refers to how exciting the contents posted by brands on social media is including humorous videos, teasers, slogans and wordplay. In addition, relaxation, emotional release, pleasure, and satisfaction with an issue or routine are all associated with entertainment (Muntinga, 2011). While for the Information, it can be defined as the content posted regarding 
Volume 3 Issue 10 (December 2021) PP. 01-13 DOI 10.35631/AIJBES.310001

how the brand shows specific products, brands, and related marketing activity. In Instagram posts, information content would be information posts about the brand.

It is also confirmed in a study that posting a post during peak hours and on weekdays has a substantial impact on online engagement. Particularly, what it means by peak hours is the posts that are being posted throughout the weekdays which are Monday through Friday. Meanwhile for the weekdays posting time can be specified as posting the posts during peak hours which are recorded from 4 p.m. to 4 a.m. (Michahelles and Cvijikj, 2013).

\section{Future Research}

There are several recommendations provided for any related future research that will later comply with this research which first is to conduct further research regarding tags, specifically to discover the number of users that tag the brands' accounts. Secondly, it is to use a questionnaire method in collecting and analysing the data to get deeper insights and validation from the audiences' perspective. Lastly, crossing to the other industry, this research also can be a benchmark to be used in any other research in larger scope outside the fashion industry such as food and beverage, or many others more.

\section{Research Implication}

This study is provided as references for the improvement of Instagram content, The result and insights of this study would help marketers gain in-depth practical understandings on how Instagram local brand could improve online engagement directly and through their Instagram posting.

This study focused on assessing the effectiveness of Instagram as marketing tools through Instagram post and primarily based on previous theoretical findings from cross-majors literature. This study could further be used as a reference for building a more comprehensive and complete model explaining how online engagement happened through Instagram post.

\section{References}

Adegbola, O., Gearhart, S., \& Skarda-Mitchell, J. (2018). Using Instagram to Engage with (Potential). The Journal of Social Media in Society, Volume 7, 232-251.

AlGhamdi, E., \& Reilly, D. (2013). Social media based business in Saudi Arabia. In: Dalhousie Computer Science In-House Conference, 1-3.

Casaló, L.V., Flavián, C., \& Ibáñez-Sánchez, S. (2017). Understanding consumer interaction on instagram: The role of satisfaction, hedonism, and content characteristics. Cyberpsychology, Behavior, and Social Networking, 20(6), 369-375.

Cvijikj, I.P., \& Michahelles, F. (2013). Online engagement factors on Facebook brand pages. Social network analysis and mining, 3(4), 843-861.

Golder, S. A., \& Huberman, B. A. (2006). Usage patterns of collaborative tagging systems. Journal of information science, 32(2), 198-208.

Haywood, D.M. (2020). For Us By Us: Innovating a 90's Streetwear Brand for Today's Fashion Industry (Doctoral dissertation, Georgetown University).

Hellberg, M. (2015). Visual Brand Communication on Instagram: A study on consumer engagement. (Available on Internet) (Master's thesis, Svenska handelshögskolan).

Hendrayati, H., \& Gaffar, V. (2016). Innovation and marketing performance of womenpreneur in fashion industry in Indonesia. Procedia-Social and Behavioral Sciences, 219, 299306. 
Volume 3 Issue 10 (December 2021) PP. 01-13 DOI 10.35631/AIJBES.310001

Instagram. (2016). Instagram statistics [Online]. Available at: http://instagram.com/press/ (Accessed at: 11 Oktober 2020).

Kabani, S. (2010). The zen of social media marketing. Benbella Books, Inc. Dallas, Texas

Kawamura, Y. (2018). Fashion-ology: an introduction to fashion studies. Bloomsbury Publishing.

Kumar S., Jacob V. S., \& Sriskandarajah C. (2006). Scheduling advertisements on a web page to maximize revenue. Eur J Oper Res 173(3):1067-1189.

Kusumah, R. (2015). Analyze the effect of trust, price, quality and perceived risk toward consumer purchase behavior in online shops Instagram. Jurnal Berkala Ilmiah Efisiensi, 15(5).

Leimkuehler, K. (2016, February 4). 3 social media engagement techniques that work. Retrieved from http://www.socialmediaexaminer.com/3-social-mediaengagementtechniques-that-work/.

Luarn, P., Lin, Y. F., \& Chiu, Y. P. (2015). Influence of Facebook brand-page posts on online engagement. Online Information Review.

Meryana, E. (2011). Retrieved October 3, 2018 from Kompas: http://health.kompas.com/read/2011/03/09/10023828/Jumat.sebagai.Hari.Sepatu. Nasional

Muder, A. (2015, February 25). Engagement Is the Best Measure of Social Media Success for Health Club. Club Industry. United States: Penton Media, Inc., Penton Business Media, Inc.

Muntinga, D. G., Moorman, M., \& Smit, E. G. (2011). Introducing COBRAs: Exploring motivations for brand-related social media use. International Journal of advertising, 30(1), 13-46.

Park, N., Kee, K.F. and Valenzuela, S., 2009. Being immersed in social networking environment: Facebook groups, uses and gratifications, and social outcomes. Cyberpsychology \& behavior, 12(6), 729-733.

Rahman, M. S., \& Mannan, M. (2018). Consumer online purchase behavior of local fashion clothing brands. Journal of Fashion Marketing and Management: An International Journal.

Rodriguez, M., Peterson, R.M. and Krishnan, V., 2012. Social media's influence on businessto-business sales performance. Journal of Personal Selling \& Sales Management, 32(3), pp.365-378.

Sharma, R., Alavi, S., \& Ahuja, V. (2017). Generating trust using Facebook-A study of 5 online apparel brands. Procedia computer science, 122, 42-49.

Wang, Y., \& Fesenmaier, D. R. (2003). Assessing motivation of contribution in online communities: An empirical investigation of an online travel community. Electronic markets, 13(1), 33-45.

Wixsite. (2015). Pure Local Brand. Retrieved April 21, 2019 from Wixsite: https://purelocalbrand.wixsite.com/home/apa-itu-local-brand

Wood, C. (2015). How to use Instagram for business and pleasure. 23 Super Effective Ways To Turn Your Instagram Followers Into Raving Fans. Amazon Digital Services 